\title{
Early assessment of diffusion and possible expansion of SARS-CoV-2 Lineage 20I/501Y.V1 (B.1.1.7, variant of concern 202012/01) in France, January to March 2021
}

Alexandre Gaymard ${ }^{1,2,3}$, Paolo Bosetti $i^{3,4}$, Adeline Feri3 ${ }^{3,5}$, Gregory Destras ${ }^{1,2}$, Vincent Enouf 6 , Alessio Andronico ${ }^{4}$, Sonia Burrel ${ }^{7}$ , Sylvie Behillil ${ }^{6}$, Claire Sauvage ${ }^{5}$, Antonin Bal ${ }^{1,2}$, Florence Morfin ${ }^{1,2}$, Sylvie Van Der Werf ${ }^{6}$, Laurence Josset ${ }^{1,2}$, ANRS MIE AC43 ${\text { COVID }-19^{8} \text {, French viro COVID group }}^{8}$, François Blanquart ${ }^{9,10}$, Bruno Coignard ${ }^{5,11}$, Simon Cauchemez ${ }^{4,11}$, Bruno Lina ${ }^{1,2,11}$

1. CNR des virus des infections respiratoires (dont la Grippe), Institut des Agents Infectieux, Hopital de la Croix Rousse, HCL, Lyon, France

2. Centre International de recherche en infectiologie (CIRI), Virpath Team, Inserm U1111, CNRS UMR5308, École Normale Supérieure de Lyon, UCBL, Université de Lyon, Lyon, France

3. These authors contributed equally

4. Mathematical Modelling of Infectious Diseases Unit, Institut Pasteur, UMR 2000, CNRS, Paris, France

5. Santé Publique France, Direction des maladies infectieuses, Saint-Maurice, France

6. CNR des virus des infections respiratoires (dont la Grippe), Molecular Genetics of RNA Viruses, CNRS UMR 3569 , Institut Pasteur, Université de Paris, Paris, France

7. GHU Pitié-Salpêtrière APHP, 83, boulevard de l'hôpital \& SU-INSERM UMR_S 1136 Team 3 THERAVIR IPLESP, Paris, France

8. The members of the group are listed under Investigators

9. Centre for Interdisciplinary Research in Biology (CIRB), Collège de France, CNRS, INSERM, PSL Research University, Paris, France

10. Infection Antimicrobials Modelling Evolution, UMR 1137, INSERM, Université de Paris, Paris, France

11. These senior authors contributed equally

Correspondence: Bruno Lina (bruno.lina@chu-lyon.fr)

Investigators: The Investigators are listed at the end of the article.

Citation style for this article:

Gaymard Alexandre, Bosetti Paolo, Feri Adeline, Destras Gregory, Enouf Vincent, Andronico Alessio, Burrel Sonia, Behillil Sylvie, Sauvage Claire, Bal Antonin, Morfin Florence, Van Der Werf Sylvie, Josset Laurence, ANRS MIE AC43 COVID-19, French viro COVID group, Blanquart François, Coignard Bruno, Cauchemez Simon, Lina Bruno. Early assessment of diffusion and possible expansion of SARS-CoV-2 Lineage 20l/501Y.V1 (B.1.1.7, variant of concern 202012/01) in France, January to March 2021. Euro Surveill. 2021;26(9):pii=2100133. https://doi.org/10.2807/1560-7917.ES.2021.26.9.2100133

The emergence of SARS-CoV-2 variant 20l/501Y.V1 (VOC-202012/1 or GR/501Y.V1) is concerning given its increased transmissibility. We reanalysed 11,916 PCRpositive tests ( $41 \%$ of all positive tests) performed on 7-8 January 2021 in France. The prevalence of 201/501Y.V1 was $3.3 \%$ among positive tests nationwide and $6.9 \%$ in the Paris region. Analysing the recent rise in the prevalence of $201 / 501 Y_{.} V_{1}$, we estimate that, in the French context, 20l/501Y.V1 is $52-69 \%$ more transmissible than the previously circulating lineages, depending on modelling assumptions.

The emergence of a variant of severe acute respiratory syndrome coronavirus 2 (SARS-CoV-2), called VOC-202012/1 (lineage B.1.1.7, 20l/501Y.V1 or GR/501Y. $V_{1}$ ) and first observed in the United Kingdom (UK), is a major concern for the management of the corona virus disease (COVID-19) pandemic [1]. It is essential to assess the current and future circulation of this variant in Europe.

\section{A nationwide survey of 501Y.V1 in France}

The SARS-CoV-2 variant 20l/501Y.V1 (501Y.V1) contains a deletion at position $69-70$ of the spike (S) protein in the target region of the ThermoFisher TaqPath PCR probe targeting the $S$ gene that leads to a loss of amplification [2]. In December 2020, the first variants with $\mathrm{S}$-gene target failure (SGTF) were detected in France through the use of the TaqPath RT-PCR (Scientific TaqPath COVID-19 Combo Kit, Thermo Fisher, Waltham, United States (US)). Since some viruses of the European lineage circulating in France can also harbour the $S$ 69-70 deletion (20A, $\left.20 \mathrm{~A}\left(\mathrm{EU}_{2}\right), 20 \mathrm{E}(\mathrm{EU} 2)\right)$, the circulation of the 501Y.V1 variant needed to be assessed by sequencing of the SGTF viruses. The first case of infection with 501Y.V1 was detected on 13 December 2020. By the end of December, $38 \%(n=87)$ of the SGTF viruses detected by the TaqPath RT-PCR had been confirmed as 501Y.V1 by sequencing [3], with a slowly increasing trend. However, the surveillance was not able to provide a robust picture of the circulation of the variant in France.

To assess the level of circulation of 501Y.V1, a nationwide survey (called Flash\#1) was implemented on 7 and 8 January. Briefly, all private and public diagnostic laboratories in Metropolitan France were asked to participate to the study on a voluntary basis by providing 
TABLE 1

National results of the Flash\#1 survey, SARS-CoV-2 diagnostic testing, France, 7-8 January 2021 ( $\mathrm{n}=183,363$ samples)

\begin{tabular}{|l|c|}
\hline Number of laboratories & 135 \\
\hline Total number of samples & 183,363 \\
\hline Number of RT-PCR positive samples & 11,916 \\
\hline Number of samples with S-gene target failure (SGTF) & 552 \\
\hline Number of samples sent for sequencing & 482 \\
\hline Number of samples successfully sequenced & 424 \\
\hline Number of 501Y.V1 sequences & 298 \\
\hline
\end{tabular}

SARS-CoV-2: severe acute respiratory syndrome coronavirus 2.

TABLE 2

Regional results of the Flash\#1 survey, SARS-CoV-2 diagnostic testing, France, 7-8 January 2021 ( $\mathrm{n}=11,916$ samples)

\begin{tabular}{|c|c|c|c|c|c|c|c|}
\hline Region & $\begin{array}{l}\text { RT-PCR } \\
\text { positive } \\
\text { (n) }\end{array}$ & $\begin{array}{l}\text { RT-PCR } \\
\text { with } \\
\text { SGTF (n) }\end{array}$ & $\begin{array}{l}\text { Samples sent } \\
\text { for sequencing } \\
\text { (n) }\end{array}$ & $\begin{array}{c}\text { Samples } \\
\text { successfully } \\
\text { sequenced (n) }\end{array}$ & $\begin{array}{c}501 Y_{.} V_{1} \\
\text { sequences } \\
\text { (n) }\end{array}$ & $\begin{array}{c}\text { Proportion of confirmed } \\
501 Y . V_{1} \text { among all the } \\
\text { successfully sequenced } \\
\text { samples (\%) }\end{array}$ & $\begin{array}{c}\text { Estimated } \\
\text { proportion of } \\
\text { 501Y.V1 cases } \\
(\%)^{\mathrm{a}}\end{array}$ \\
\hline Auvergne-Rhône-Alpes & 2,405 & 68 & 60 & 46 & 26 & $56.5 \%$ & $1.6 \%$ \\
\hline Bourgogne-Franche Comté & 585 & 39 & 38 & 37 & 1 & $2.7 \%$ & $0.2 \%$ \\
\hline Brittany & 307 & 18 & 7 & 7 & 1 & $14.3 \%$ & $0.8 \%$ \\
\hline Centre-Val de Loire & 523 & 23 & 23 & 20 & 16 & $80.0 \%$ & $3.5 \%$ \\
\hline Grand Est & 805 & 40 & 30 & 18 & 4 & $22.2 \%$ & $1.1 \%$ \\
\hline Hauts de France & 482 & 16 & 11 & 9 & 7 & $77.8 \%$ & $2.6 \%$ \\
\hline Ile-de-France & 2,149 & 158 & 145 & 132 & 124 & $93.9 \%$ & $6.9 \%$ \\
\hline Nouvelle Aquitaine & 512 & 13 & 3 & 3 & 2 & $66.7 \%$ & $1.7 \%$ \\
\hline Normandy & 428 & 9 & 9 & 9 & 5 & $55.6 \%$ & $1.2 \%$ \\
\hline Occitanie & 339 & 10 & 8 & 4 & 4 & $100.0 \%$ & $2.9 \%$ \\
\hline $\begin{array}{l}\text { Provence-Alpes-Côte } \\
\text { d'Azur }\end{array}$ & 1,881 & 105 & 96 & 88 & 75 & $85.2 \%$ & $4.8 \%$ \\
\hline Pays de la Loire & 513 & 19 & 18 & 17 & 6 & $35.3 \%$ & $1.3 \%$ \\
\hline France (not attributable) ${ }^{\mathrm{b}}$ & 987 & 34 & 34 & 34 & 27 & $79.4 \%$ & $2.7 \%$ \\
\hline $\begin{array}{l}\text { Total Metropolitan France } \\
\text { (without Corsica) }\end{array}$ & 11,916 & 552 & 482 & 424 & 298 & $70.3 \%$ & $3.3 \%$ \\
\hline
\end{tabular}

SARS-CoV-2: severe acute respiratory syndrome coronavirus 2; SGTF: S-gene target failure.

a This estimate is calculated by applying the proportion of confirmed 501Y.V1 among all the successfully sequenced samples to the fraction of RT-PCR with SGTF over all the RT-PCR positives.

${ }^{b}$ Results from several laboratories processing samples from metropolitan France.

to the National Reference Centre the number of SARSCoV-2 PCR tests carried out during these 2 days and the number of PCR-positive tests. In addition, the laboratories were asked to test all their SARS-CoV-2 PCRpositive specimens with the TaqPath Kit. Subsequently, all SGTF specimens were sequenced for confirmation of lineage.

During the 2-day survey, we also collected the total number of SARS-CoV-2 diagnostic tests performed by RT-PCR and the number of positive tests in France to assess the representativeness of the survey.

\section{Level of circulation of 501Y.V1 across France}

Overall, 135 laboratories located in all regions of France contributed to the Flash\#1 survey (Table 1). A total of 183,363 RT-PCR tests were included in the survey, with 11,916 positive. This represented $36 \%$ of all SARS-CoV-2 PCRs performed in France during these 2 days, and $41 \%$ of the PCR-positive tests reported in France during this period. Among the 11,916 positive tests, 552 (4.6\%) had the SGTF profile. Of those, $424(76.8 \%)$ were successfully sequenced either by Sanger sequencing (S gene) or whole genome sequencing (WGS; Illumina, San Diego, US). The sequencing detected 298 cases with $501 Y . V_{1}$ viruses among the 424 (70.3\%). As a consequence, we estimate that $70.3 \%$ of 


\section{A. Number of PCR-positive tests per} 100,000 inhabitants

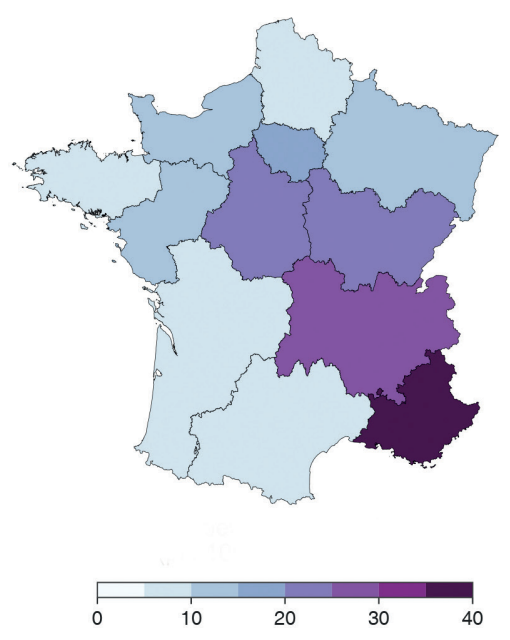

B. Number of $501 Y . V_{1}$ sequences per 100,000 inhabitants
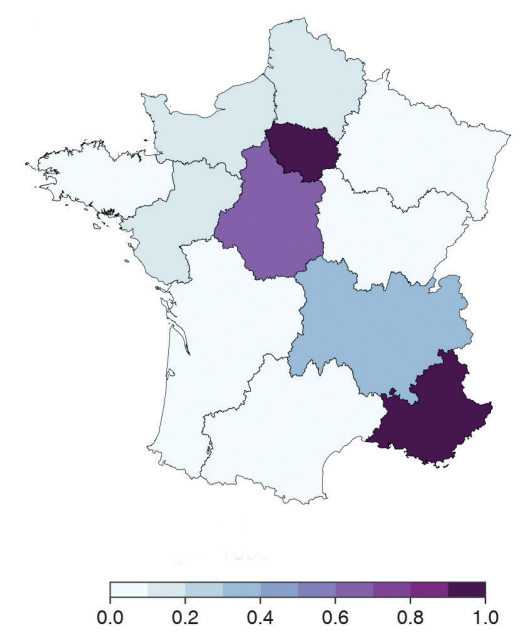
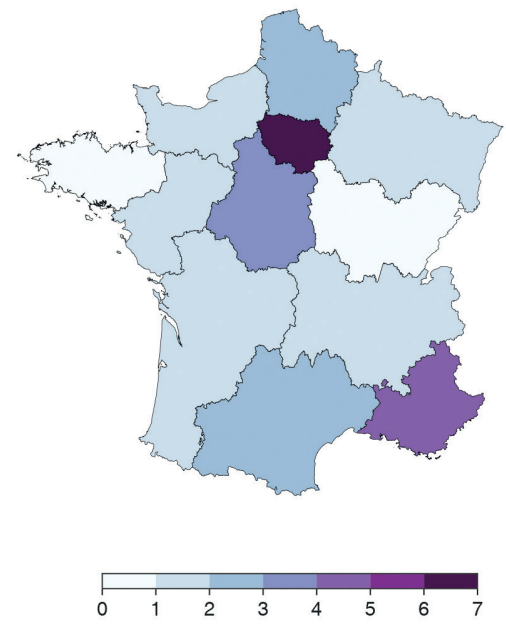

the 552 SGTF viruses were $501 \mathrm{Y} . \mathrm{V}_{1}$ viruses, representing $3.3 \%$ of all SARS-CoV-2 detections (Table 2 ).

Regional disparities were observed. The prevalence of $501 \mathrm{Y} . \mathrm{V}_{1}$ among cases ranged from $0.2 \%$ in the Bourgogne-Franche Comté region to $6.9 \%$ in $l l e-d e-$ France (Table 2 and Figure 1). In particular, about two thirds of $501 \mathrm{Y}_{\mathrm{V}} \mathrm{V}_{1}$ were observed in Ile-de-France and Provence-Alpes-Côte d'Azur, the two regions which had the largest proportions of 501Y.V1 among samples (6.9\% and $4.8 \%$, respectively).

\section{Estimates of increased transmissibility of 501Y.V1 in France}

A second survey (Flash\#2) [4] was performed on 27 January 2021 and found a prevalence of 501Y.V1 of $13.0 \%$ $(1,335$ of 10,261 tests PCR-positive for SARS-CoV-2) on that date (Supplement). We analysed the growth in the prevalence of $501 Y . V_{1}$ between Flash\#1 and Flash\#2 to estimate the increased transmissibility of $501 Y . V_{1}$ relative to the classical European lineage viruses. In our baseline scenario, we assume that the effective reproduction number $\left(R_{\text {eff }}\right)$ of the classical lineages was 1.0 on average between the surveys [5] and that all viruses had a gamma-distributed generation time with a mean of 6.5 days and a coefficient of variation of 0.62 [1]. We estimated that the 501 Y.V1 variant was $59 \%$ ( $95 \%$ credible interval $(\mathrm{Crl}): 54-65 \%)$ more transmissible than the classical lineages, consistent with estimates from the UK [1] (Figure 2A). In sensitivity analyses, we showed that the estimated competitive advantage of $501 \mathrm{Y} \mathrm{V}_{1}$ would be little affected by changes in our assumptions about the $R_{\text {eff }}$ of the classical lineages during the study period (Figure $2 \mathrm{~A}$ ). A lower generation time with a mean of 5.5 days and a coefficient of variation of 0.33 for both viruses would reduce the competitive advantage to $52 \%$ (95\% Crl: $47-57 \%$ ) (Figure $2 \mathrm{~B}$ ). Estimates of the competitive advantage would increase to $69 \%$
(95\% Crl: $64-76 \%$ ) if the generation time of $501 \mathrm{Y} . \mathrm{V}_{1}$ was 1 day longer than that of the classical lineages [6] (Figure 2C).

We used these estimates to assess future trends of the proportion of $501 \mathrm{Y}_{\mathrm{V}} \mathrm{V}$ infections in France, considering different scenarios for the $R_{\text {eff }}$ of the previously circulating lineages, ranging from 0.9 to 1.1 for the coming months. For $R_{\text {eff }}=1.0$, we estimated that the proportion of $501 Y . V_{1}$ cases would reach $66 \%$ (95\% Crl: $61-71 \%)$ and 96 (95\% Crl: $94-97 \%)$ by 1 March and 1 April 2021, respectively (Figure 2D). The predicted trajectory closely matched two recent estimates of the prevalence of $501 \mathrm{Y}_{\mathrm{V}} \mathrm{V}_{1}$ that were not used for inference (Figure 2D) $[7,8]$ (Supplement).

As the prevalence of $501 \mathrm{Y}_{\mathrm{V}} \mathrm{V}_{1}$ increases, we expect that the population-level $R_{\text {eff }}$ (i.e. the one averaged across the different variants) will be respectively 39\% (95\% Crl: $33-45 \%)$ and $56 \%$ (95\% Crl: $50-62 \%)$ higher on 1 March and 1 April 2021 than what would be expected if only the classical lineages were circulating (Figure $2 \mathrm{E}$ ). These results were little affected when we changed the values for the $R_{\text {eff }}$ of the previously circulating lineages (Figure $2 \mathrm{D}$ and $\mathrm{E}$ ).

\section{Conclusion}

This first round of investigation has emphasised the need for strengthening the SARS-CoV-2 genomic surveillance through rapid and accurate monitoring of current and future variants. As a consequence, repeated flash surveys are now scheduled, and a national SARSCoV-2 genomic surveillance scheme coordinated by Santé publique France, the national research agency for AIDS and viral hepatitis/emerging infectious diseases (Agence nationale de recherches sur le sida et les hépatites virales/Maladies infectieuses émergentes (ANRS/MIE)) and the National Reference Laboratory 
Estimated increase in transmissibility of the 501Y, Flash surveys, France, January 2021

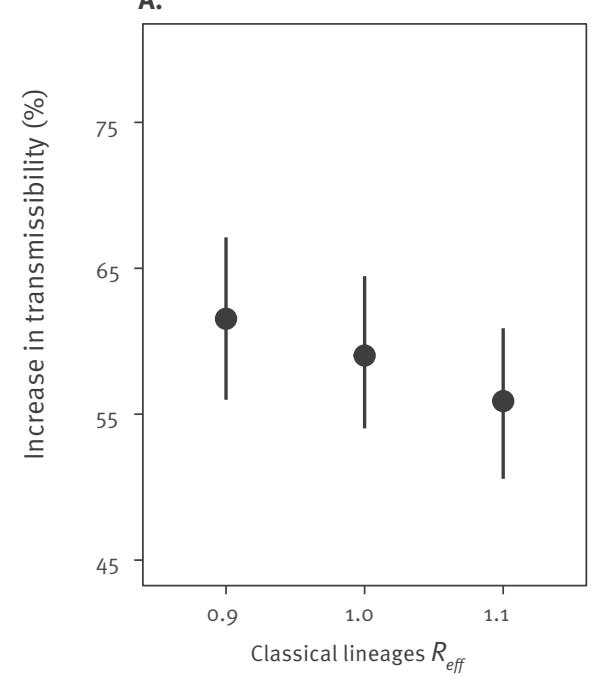

D.

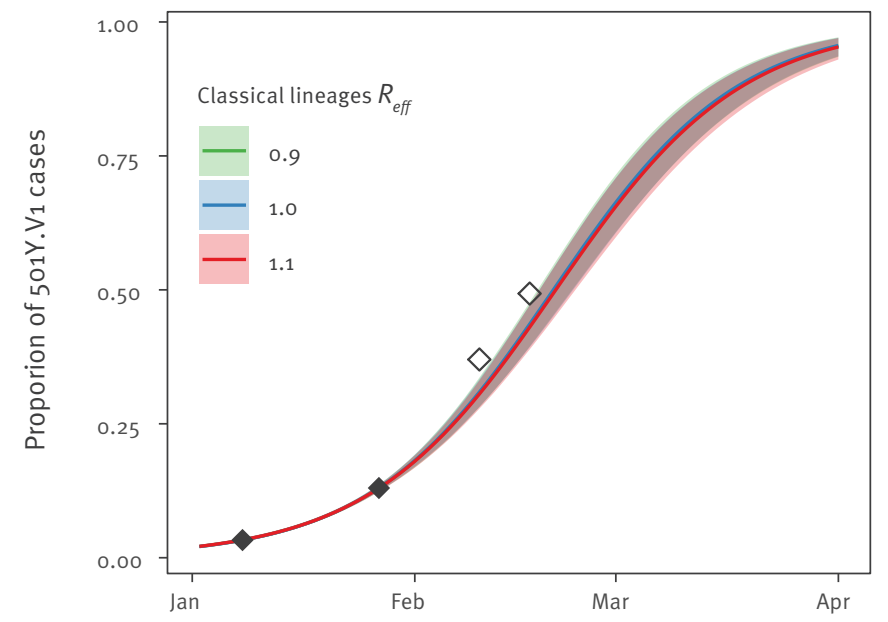

B.

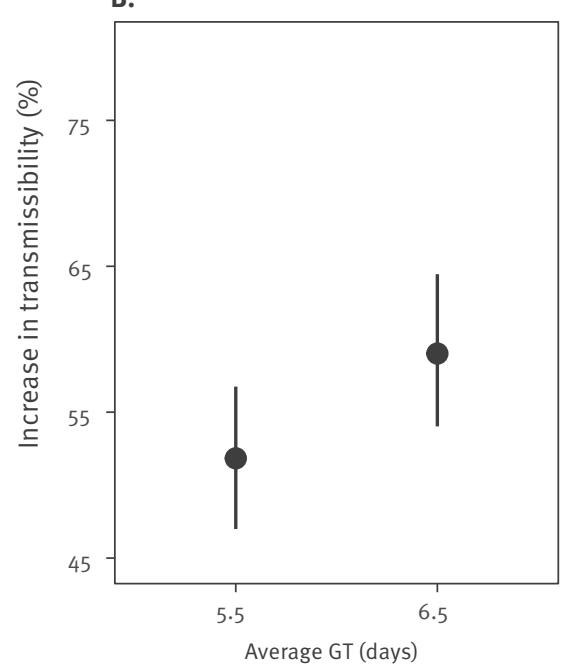

C.

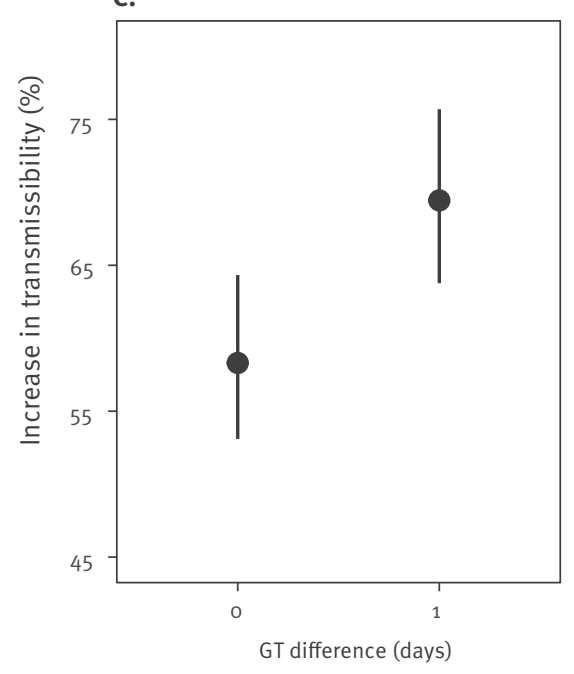

E.

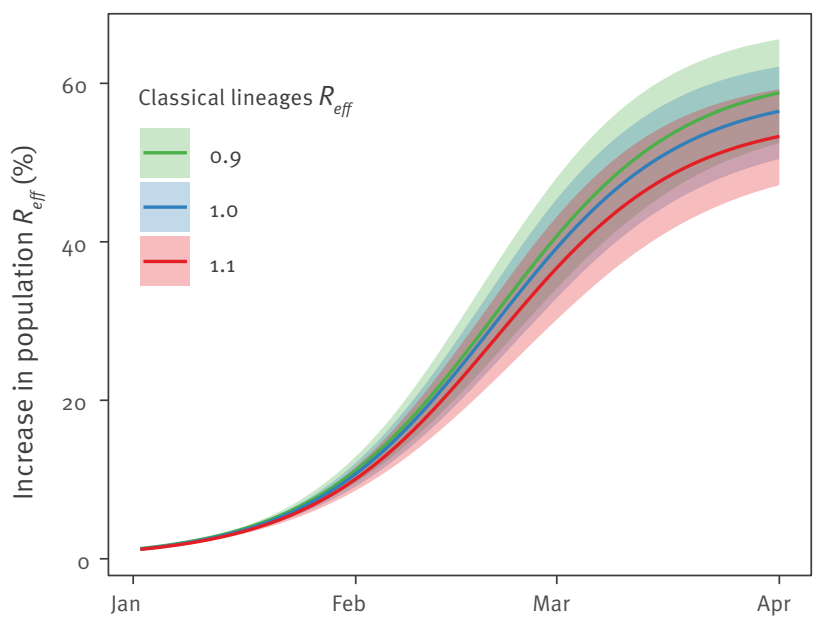

GT: generation time; $R_{\text {eff }}$ : effective reproduction number; SARS-CoV-2: severe acute respiratory syndrome coronavirus 2.

A-C. Increased transmissibility of 501Y.V1 variant relative to the classical European lineages, under different assumptions for the GT distribution and the $R_{\text {eff }}$ of the classical European lineages.

A. GT distribution with a mean of 6.5 days and a coefficient of variation of 0.62 for both viruses (baseline) for $R_{\text {eff }}$ ranging from 0.9 to 1.1 .

B. Comparing the baseline estimates to those obtained using a GT distribution with a mean of 5.5 days and coefficient of variation of 0.33 for both viruses and for $R_{\text {eff }}=1.0$.

C. Increasing the mean GT of the variant from 6.5 (GT difference $=0)$ to 7.5 (GT difference $=1)$.

D. Temporal trends for the proportion of 501Y.V1 among SARS-CoV-2 cases.

E. Temporal trends for the expected increase in the effective reproduction number of a person infected with SARS-CoV-2 (averaged across the different variants) in France relative to a scenario where 501Y.V1 would not be circulating in France.

The trends are shown for three values of Reff ( 0.9 in green, 1.0 in blue, and 1.1 in red). In panels A, B and C, dots represent posterior means while vertical bars represent $95 \%$ credible intervals. In panels D and E, solid lines represent posterior means while ribbons represent $95 \%$ credible intervals. In panel D, filled diamonds represent data from Flash\#1 and Flash\# 2 used for model calibration; empty diamonds are external validation data (not used for model calibration). 
for respiratory viruses (including influenza) has been implemented, based on the reinforcement of four sequencing platforms to increase national sequencing capacities and accelerate sequence determination. In addition, the French health authorities promote the implementation of PCR-specific tools (detection of the $501 \mathrm{Y}$ and $484 \mathrm{~K}$ single nucleotide polymorphisms) to enhance the screening capacity of laboratories. Further, randomly selected specimens will be analysed by the sequencing platforms. This strategy will address two complementary objectives, improved monitoring and real-time measurement of the impact of existing variants and rapid detection of newly emerging variants. In parallel, mathematical models anticipate how the rise of $501 Y . V_{1}$ and other variants may affect the course of the pandemic and the impact of control measures $[9,10]$. It will also be important to determine how spatial heterogeneities in the spread of variants may affect control strategies.

\section{Investigators}

ANRS MIE AC43 COVID-19: Elyanne Gault, Frédérique Moreau, Ségolène Brichler, Héloïse Delagrèverie, Diane Descamps, Charlotte Charpentier, Flore Rozenberg, AnneSophie L'Honneur, David Veyer, Laurent Bélec, Slim Fourati, Christophe Rodriguez, Jean-Michel Pawlotsky, Jacques Fourgeaud, Hanène Abid, Anne-Marie Roque-Afonso, Honorine Fenaux, Aude Jary, Stéphane Marot, Maud Salmona, Marie-Laure Chaix, Laurence Morand-Joubert, Aurélie Schnuriger, Stéphanie Marque Juillet, Pauline Bargain, Cécile Poggi, Lionel Chollet, Clémence Guillaume, Jérôme Guinard, Sophie Vallet, Léa Pilorgé, Evelyne Schvoerer, Cédric Hartard, Sandrine Castelain, Catherine François, Alexandra Ducancelle, Caroline Lefeuvre, Quentin Lepiller, Solène Marty-Quinternet, Pantxika Bellecave, Camille Tumiotto, Julia Dina, Meriadeg Le Gouil, Cécile Henquell, Audrey Mirand, Raymond Césaire, Alexis de Rougemont, Christelle Auvray, Sylvie Larrat, Benjamin Némoz, Claire Tinez, Aurélie Guigon, Sébastien Hantz, Sylvie Rogez, Georges Dos Santos, Pascale Perez, Christelle Jost, Brigitte Montes, Vincent Foulongne, Berthe-Marie Imbert, Céline Bressollette, Valérie Giordanengo, Géraldine Gonfrier, Magali Garcia, Nicolas Lévêque, Véronique Brodard, Hélène Moret, Vincent Thibault, Anne Maillard, Marie-Christine Jaffar-Bandjee, Marie Gueudin, Jean-Christophe Plantier, Bruno Pozzetto, Sylvie Pillet, Samira Fafi-Kremer, Morgane Solis, Jacques Izopet, Pauline Trémeaux, Karl Stefic, Lynda Handala, Geneviève Billaud, Emilie Frobert, Audrey Mérens, Christine Bigaillon, Marine Desroches, Cédric Thepenier, Frédéric Janvier, Marie-Pierre Otto, Bénédicte Roquebert, Stéphanie Haïm-Boukobza;

French viro COVID group: Jean-Baptiste Bour, Amélie Brousse, Laura Isabelle Verdier, Laura Billon, Anne-Cécile Hochart, Benoît Bergues, Cécile Jensen, Anne Dao Dubremetz, Stéphanie Van Agt, Salma Ben Hadj Yahia, Fabienne SoulaScheffer, Ludovic Bergon, Béatrice Lesimple, Dominique Descamps, Franck Bernardi, Marie-Pierre Weillaert, Sophie Dekeyser, Lucas Dehove, Bertrand Maubert, Christine Pucalowski, Agathe Francart, Manica Vasseur, Ines Vergnole, Pierre Lureau, Philippe Gueudet, Pascale Martres, Elodie Collin, Anne Vachee, Elena Guillotel, Pierre Sabatier, Véronique Decroix, Zinédine Benchikh, Cécile Faruggia, David Girard, Anne-Marie Camin-Ravenne, Pierre Patoz, Jacques Sartre, Frédérique Canis, Anne Cady, Camille Corlouer, Mounira Smati-Lafarge, Juliette Gillon-Humbert, Jérémie Violette, Alain Gravet, Ana Mendes, Cécile Poggi, Sophie Poussing, Cyrille Bonnet, Jean-François Comes,
Frédérique Roumanet, Vianney Leclercq, Jonas Amzalag, Fabien Cabanne, Emmanuel Chanard, Gwenolé Pringent, Aude Lesenne, Stephanie Arsene, Jean-Christophe Roig, Laurence Prots, Claire Felloni, Bénédicte Druel, Catherine Coignard, Michel Tartary, Stéphanie Gilard

\section{${ }^{*}$ Author's correction}

On request of the authors, a recognition of the laboratories belonging to the ColVHB network was added to the Acknowledgements section after publication of the article. This addition was made on 5 March 2021.

\section{Acknowledgements}

We thank Florence Lot, Maria-Clara Da Costa, Pierre Pichon, Charly Ramus, Etienne Simon-Lorrière, Florence Debarre, Vittoria Colizza, Pascal Crépey and Juliette Paireau for their contribution. We acknowledge financial support from Santé publique France (the French national public health agency), the French Ministry of health (Grant COVIDseq), the Consortium for the surveillance and research on emerging pathogens via microbial genomics (EMERGEN) coordinated by Santé publique France and ANRS Maladies Infectieuses Emergentes, the Investissement d'Avenir programme, the Laboratoire d'Excellence Integrative Biology of Emerging Infectious Diseases programme (grant ANR-10-LABX-62IBEID), the European Union's Horizon 2020 research and innovation programme under grants 101003589 (RECOVER). This work has been supported by the laboratories belonging to the ColvHB network*.

\section{Conflict of interest}

None declared.

Authors' contributions

$A G, A F, G D, V E, S B, S B, C S, A B, F M, S V D W, L J$, ANRS MIE $A C 43$ COVID-19, French viro COVID group, $B C, B L$ performed the survey. $\mathrm{PB}, \mathrm{AA}, \mathrm{FB}$ and $\mathrm{SC}$ did the modelling. $\mathrm{PB}, \mathrm{SC}$ and $B L$ wrote a first draft. All authors critically edited the draft.

\section{References}

1. Volz Erik, Mishra S, Chand M, Barrett JC, Johnson R, Geidelberg L, et al. Transmission of SARS-CoV-2 lineage B.1.1.7 in England: insights from linking epidemiological and genetic data. medRxiv. 2020.12.30.20249034. https://doi. org/10.1101/2020.12.30.20249034

2. Bal A, Destras G, Gaymard A, Stefic K, Marlet J, Eymieux S, et al. Two-step strategy for the identification of SARS-CoV-2 variant of concern 202012/01 and other variants with spike deletion H69-V70, France, August to December 2020. Euro Surveill. 2021;26(3):2100008. https://doi.org/10.2807/15607917.ES.2021.26.3.2100008 PMID: 33478625

3. Sante Publique France. COVID-19: point épidémiologique du 28 janvier 2021. [COVID-19: epidemiological update of 28 January 2021]. Paris: Santé Publique France; 2021. French. Available from: https://www.santepubliquefrance.fr/maladieset-traumatismes/maladies-et-infections-respiratoires/ infection-a-coronavirus/documents/bulletin-national/ covid-19-point-epidemiologique-du-28-janvier-2021

4. Sante Publique France. COVID-19: point épidémiologique du 14 janvier 2021. [COVID-19: epidemiological update of 14 January 2021]. Paris: Santé Publique France; 2021. French. Available from: https://www.santepubliquefrance.fr/maladieset-traumatismes/maladies-et-infections-respiratoires/ infection-a-coronavirus/documents/bulletin-national/ covid-19-point-epidemiologique-du-14-janvier-2021

5. Sante Publique France. COVID-19: point épidémiologique du 11 février 2021. [COVID-19: epidemiological update of 11 February 2021]. Paris: Santé Publique France; 2021. French. 
Available from: https://www.santepubliquefrance.fr/maladieset-traumatismes/maladies-et-infections-respiratoires infection-a-coronavirus/documents/bulletin-national/ covid-19-point-epidemiologique-du-11-fevrier-2021

6. Kissler S, Fauver JR, Mack C, Tai CG, Breban MI, Watkins AE, et al. Densely sampled viral trajectories suggest longer duration of acute infection with B.1.1.7 variant relative to non-B.1.1.7 SARS-CoV-2. 2021. Preprint. Available from: https://nrs. harvard.edu/URN-3:HUL.INSTREPOS:37366884

7. Sante Publique France. COVID-19 Point épidémiologique du 18 février 2021. [COVID-19: epidemiological update of 18 February 2021]. Paris: Santé Publique France; 2021. French. Available from: https://www.santepubliquefrance.fr/maladieset-traumatismes/maladies-et-infections-respiratoires/ infection-a-coronavirus/documents/bulletin-national/ covid-19-point-epidemiologique-du-18-fevrier-2021

8. Sante Publique France. COVID-19 Point épidémiologique du 25 février 2021. [COVID-19: epidemiological update of 25 February 2021]. Paris: Santé Publique France; 2021. French. Available from: https://www.santepubliquefrance.fr/maladieset-traumatismes/maladies-et-infections-respiratoires/ infection-a-coronavirus/documents/bulletin-national/ covid-19-point-epidemiologique-du-25-fevrier-2021

9. Bosetti P, Kiem CT, Andronico A, Paireau J, Levy Bruhl D, Lina $B$, et al. A race between SARS-CoV-2 variants and vaccination: The case of the B.1.1.7 variant in France. 2021. pasteur-03149525.le from: https://hal-pasteur.archivesouvertes.fr/pasteur-03149525/document

10. Di Domenico, Laura, Giulia Pullano, Chiara E. Sabbatini, Daniel Lévy-Bruhl, and Vittoria Colizza. Impact of January 2021 social distancing measures on SARS-CoV-2 B. 1.1. 7 circulation in France. medRxiv. 2021.02.14.21251708. https:// doi.org/10.1101/2021.02.14.21251708

\section{License, supplementary material and copyright}

This is an open-access article distributed under the terms of the Creative Commons Attribution (CC BY 4.0) Licence. You may share and adapt the material, but must give appropriate credit to the source, provide a link to the licence and indicate if changes were made.

Any supplementary material referenced in the article can be found in the online version.

This article is copyright of the authors or their affiliated institutions, 2021. 